\title{
La lectura en educación básica: un saber dominante, sometido e híbrido
}

\author{
Reading in basic education: a dominant, \\ subject and hybrid knowledge
}

Patricia Barrera Delgado**

RESUMEN

Desde una perspectiva foucaultiana se aborda la lectura como un saber que se conforma dominante, sometido e híbrido. Como saber dominante, se cuestiona la comprensión lectora que cobró forma desde una historia de la lectura que trasciende en la actualidad, se refuerza y se distribuye de la escuela al aula con un discurso de mejora que instaura prácticas evaluadoras. Se usa la historia oral de algunas maestras de educación primaria como recurso metodológico, donde se manifiesta una experiencia de la que emerge el saber sometido de la lectura, que tiene que ver con sus modos de leer en un tiempo y espacio determinados, que cuenta su vida, afectos, necesidades, las relaciones que establece con el otro y le permite la construcción del significado de un texto; este saber sometido pasa inadvertido ante la exigencia del leer para comprender, es un saber que nunca trasciende al corpus teórico institucionalizado por ser subjetivo. Así en el aula, ambos saberes, comprensión y experiencia-subjetividad, permean el pensamiento y las acciones del maestro para conformarse como el saber híbrido que juega con lo instituido. A su vez, los relatos permiten reconocer una diversidad de saberes de la lectura que dan posibilidad a otras formas de subjetivación.

Palabras clave: lectura-saber, saber dominante, saber sometido, saber híbrido, comprensión lectora, experiencia de la lectura

\section{ABSTRACT}

This article discusses reading from a Foucauldian perspective, as a type of knowledge that is dominant, subjugated, and hybrid. The article questions reading comprehension as a dominant type of knowledge that emerged from a history of reading that transcends to this day, and that is reinforced and distributed from schools to classrooms along with an improvement discourse associated to the implementation of assessment practices. Oral history as a methodological resource was used to recover the stories of primary education teachers. Reading as a subjugated knowledge emerges from their experiences: a knowledge related to ways of reading in a specific time and place. This type of reading retells their lives, emotions, and relationships; and enables them for the construction of the meaning of texts. This subjugated knowledge goes unnoticed, and it is never considered within the theoretical institutionalized corpus, since it is subjective: only reading comprehension is taken into account. Both types of knowledge (reading comprehension and reading as a subjective experience), permeate teachers' thoughts and actions, and they form a hybrid knowledge that challenges instituted knowledge. The teachers' stories also show a diversity of knowledges related to reading which allow for other forms of subjectivity.

Key words: reading-knowledge, dominant knowledge, subjugated knowledge, hybrid knowledge, reading comprehension, reading experience

* El artículo se desprende de la investigación doctoral, en proceso, denominada: "La evaluación de la lectura: Dispositivo y Subjetivación".

** Tesista del Doctorado en Ciencias de la Educación del Instituto Superior de Ciencias de la Educación del Estado de México (ISCEEM); depba@yahoo.com.mx 


\section{INTRODUCCIÓN}

En este artículo me propongo reflexionar sobre el saber de la lectura, un saber que se mira con gran insistencia en la escuela desde hace más de una década, después de que se dieron a conocer los resultados del Programa para la Evaluación Internacional de Estudiantes (PISA, por sus siglas en inglés) de la Organización para la Cooperación y el Desarrollo Económicos (OCDE), aplicado en nuestro país desde 2000, fecha a partir de la que los resultados reportan a México en los últimos lugares en comprensión lectora. ${ }^{1}$ Como consecuencia, proliferan las investigaciones ${ }^{2}$ sobre este tema y se pone de manifiesto una preocupación constante por incrementar la lectura, no solo en las escuelas, sino también entre la sociedad. ${ }^{3}$

Pero, ¿cómo mejorar la comprensión lectora? En años recientes, con la Reforma Integral de Educación Básica (RIEB), la preocupación se desplazó de la comprensión hacia la competencia lectora. Sin embargo, el presente análisis no se propone dar respuestas a las preocupaciones de los bajos niveles obtenidos por los alumnos mexicanos en la prueba PISA, de las que otras investigaciones ya se ocupan hoy en día, sino de situarla como un saber dominante de la lectura; es decir, un saber que a lo largo de la historia de la educación en nuestro país ha sido básico y hegemónico, que en su conformación ha dejado a otros saberes de la lectura excluidos, enmascarados y descalificados. Desde esta lógica, la lectura cobra forma entre un saber dominante como el de la comprensión lectora sobre los saberes sometidos, llamaré así a la lectura del mundo, a aquella como experiencia y a los saberes híbridos que construyen los maestros de educación primaria.

\footnotetext{
${ }^{1}$ Por mencionar un dato de los resultados de este programa, en 2003 el periódico La Jornada publicó que México quedó en el lugar 34 entre los 41 países que participaron, y aunque escalaron el penúltimo lugar que ocuparon los estudiantes en 2000, las cifras continuaron siendo desalentadoras.

${ }^{2}$ El estado del arte de la investigación que se realizó en el ISCEEM, "La evaluación de la lectura: Dispositivo y Subjetivación", da cuenta de una serie de pesquisas de 2010 hasta la fecha; la mayoría parte de analizar los bajos resultados obtenidos en PISA.

${ }^{3}$ En México se realiza una campaña para fomentar la lectura que invita a los padres de familia a leer con sus hijos 20 minutos diarios, instala una serie de frases en las estaciones del metro, paradas de metrobús, trolebús, espectaculares pegados en los camiones, etc., que reflejan una preocupación por la lectura; pero, ¿qué tipo de lectura es la que se promueve?: "Leer nos enloquece", "Leer es mi acto favorito", "Leer es mi mejor canción", "Leer 20 minutos al día"; en estas frases la lectura no se manifiesta como el acto de dar significado a la vida y al mundo.
} 
Para analizar la lectura de comprensión como un saber dominante sobre los sometidos e híbridos recurro a Michel Foucault que, en su libro Defender la sociedad, caracteriza a los saberes sometidos, primero, como los "contenidos históricos que fueron sepultados, enmascarados en coherencias funcionales o sistematizaciones formales" y, en segundo lugar, como una "serie de saberes que estaban descalificados como saberes no conceptuales, como saberes insuficientemente elaborados: saberes ingenuos, saberes jerárquicamente inferiores, saberes por debajo del nivel de conocimiento o de la cientificidad exigidos" (1997/2002: 15-31); más adelante también los describe como el saber de la gente.

El saber dominante, a diferencia del sometido, cobra forma desde el discurso de la ciencia: unitario, formal, científico, integrado como instancia teórica que se distribuye y refuerza, en una sociedad como la nuestra, en instituciones como la escuela, en un aparato pedagógico o político, asumiendo un orden, el del discurso. Distribución y refuerzo provocan una línea abismal que niega toda posibilidad a la emergencia de otro saber; nos somete a la ignorancia de otro decir, conocer o pensar; se conforma una capa que invisibiliza otras posibilidades de conocimiento, y queda establecida una única verdad sobre el saber de la lectura.

La distribución y el refuerzo de la serie de discursos que promueve mejorar la comprensión lectora del alumno, centran su práctica en el aula desde la evaluación, sea esta PISA, o bien en los hechos ocurridos en 2009, cuando surgió la propuesta de evaluar velocidad lectora, fluidez y comprensión con el Manual de procedimientos para el fomento y la valoración de la competencia lectora. ${ }^{4}$ En 2013 la Secretaría de Educación Pública (SEP) reconoció que esta valoración tenía un enfoque equivocado, por lo que cambió nuevamente los criterios: recuperar información, formarse una comprensión general, desarrollar una interpretación, reflexionar sobre el contenido de un texto y sobre su forma. ${ }^{5}$ Tanto PISA, como la propuesta del manual o la renovación del enfoque buscan una respuesta a la lectura verificable, que clasifica al lector, de

\footnotetext{
${ }^{4}$ Este manual se puede revisar en el documento titulado "Habilidad Lectora". Disponible, en www.leer.sep.gob.mx

${ }^{5}$ El documento "Propuesta para la renovación de la sección 'Competencia lectora' en el reporte de evaluación”, disponible en www.consultasrodac.sep.gob.mx/reporte_evaluación_comprensión.pdf
} 
ahí el uso de niveles lectores, ${ }^{6}$ y por lo tanto anulan la posibilidad de que diferentes lectores den diversas lecturas; el lector cazador y furtivo $^{7}$ no puede surgir entre los que deben lograr un nivel. Un único concepto de lectura circula en la evaluación que coacciona nuestra voluntad de saber.

Al ser la evaluación una práctica sostenida por un sistema de instituciones, refuerza el dominio de un saber por medio de la exclusión, la prohibición y la separación, el saber de las maestras -por ejemplo-. Un saber sometido que se conforma de las lecturas que realizó de niña, sus primeros contactos con los libros, sus emociones o aberraciones hacia un texto en particular (emociones que no podemos ver, verificar, mucho menos cuantificar) y que, sin embargo, en la adultez la llaman para tocar su ser -lo mueven y lo conmueven- para jugar entre el saber dominante y hegemónico que le ha impuesto la escuela y que ahora, como maestro, debe promover.

El saber lector de algunas maestras recuperado con la investigación se mueve en lo instituido, lo nutre y lo inviste el mismo discurso: mejorar la comprensión lectora, su saber ahora híbrido y sometido, emerge en el aula con sus alumnos, en su intimidad o en relación con sus compańeros, pero nunca trasciende al corpus teórico del saber institucionalizado. La emergencia de los saberes sometidos fue posible mediante el recurso metodológico de la historia oral de la que hablaré más adelante.

Por lo tanto, si Foucault ubica en el saber sometido el del loco, el delincuente, como un saber que no es común, sino al contrario, que es particular, un saber local, regional, un saber diferencial, incapaz de unanimidad y De la Fuente (2007: 132) hace referencia con este saber al del ciudadano marginal, el del campesino, el enfermo, el de los niños, los ancianos, el de los chamanes, los prisioneros, etc., entonces yo sitúo en la misma condición el saber de las maestras. Un saber que tiene que ver con sus modos de leer en un tiempo y un espacio, que tiene y ha tenido que responder a

\footnotetext{
${ }^{6}$ Las tres propuestas que menciono en el texto recurren al uso de Niveles Lectores: PISA opta por clasificarlos del nivel 1 al 6, cada uno con sus características, el manual propone ubicar al alumno en estándar, se acerca al estándar, avanzado o requiere apoyo, y la actual propuesta recurre a una escala Lickert: siempre, casi siempre, en ocasiones, requiere apoyo adicional.

${ }^{7}$ De acuerdo con De Certeau, no hay un lector fundante, el lector carece de lugar al ser un viajero: "circulan sobre las tierras del prójimo, nómadas que cazan furtivamente a través de los campos que no han escrito, que roban los bienes de Egipto para disfrutarlos" (2010: 187).
} 
una serie de exigencias institucionales, unas veces la familia, otras la escuela; un saber de la lectura que está relacionado también con el sentir, con su vida, con los vínculos que establece con el otro, con su mundo, que le dan pie a la construcción de un significado único de la lectura de un texto; único, pero con poder de transformación. Así, el saber sometido de la lectura que han construido se mueve casi inadvertido, bajo el leer para comprender, como competencia, leer para divertirse, para lograr indicadores y cumplir con lo solicitado por PISA, que en la actualidad se pretende cumplir desde una evaluación de la lectura.

Mi pretensión no es descalificar al saber dominante de la lectura, sino hacer notar que con su dominio provoca la exclusión de otros, que podrían permitir diversas posibilidades de sentido de la lectura o brindarla a los saberes sometidos de jugar con la hegemonía de un saber lector institucionalizado; asimismo, poner a ambos sobre la mesa para crear una oposición que dé lugar a otro tipo de pensamiento y reconsiderar otras formas de lectura, alejarnos de esa visión que Alfaro (2007) ha dado bien en llamar romántica y democrática, ante la cual el lector, frente a su texto, es igual a todos los lectores; confiar en la autonomía al lector. Reconocer la diversidad de los saberes para dar posibilidad a otras formas de subjetivación en el sujeto.

Esta pretensión implica que interrogue el dominio del concepto comprensión lectora: ¿¿de qué manera se conformó como un saber dominante dentro de la institución escolar? A partir de este planteamiento, el artículo se desarrolla desde dos ejes de reflexión, lectura y comprensión: una mirada retrospectiva, y la experiencia de la lectura: un saber sometido. Antes de desarrollar los puntos de análisis, realizo una breve descripción de la metodología usada en la investigación.

\section{MetodologíA}

Si bien es cierto que en la actualidad los hechos educativos se pueden abordar para su análisis e interpretación desde diversas metodologías cualitativas, la historia oral ${ }^{8}$ como recurso metodo-

\footnotetext{
${ }^{8}$ De acuerdo con Collado (2006: 13) “... la historia oral es una metodología creadora o productora de fuentes para el estudio de cómo los individuos (actores, sujetos, protagonistas, observadores) perciben y/o son afectados por los diferentes procesos históricos de su tiempo".
} 
lógico me permitió recuperar lo que las maestras cuentan sobre un acontecimiento particular, en un espacio y tiempo determinado: evaluar la lectura con el manual. Las maestras se situaron en el papel de narradoras, y yo, como investigadora-entrevistadora, con una guía flexible de preguntas, establecimos una conversación abierta de la que emanó una experiencia que, de acuerdo con Larrosa (2007: 68) es lo que te implica, te afecta, te marca, te deja huella; y para Foucault (1978/2013: 33) es algo de lo que uno sale transformado, para no pensar lo mismo que antes.

Para elaborar el guion de entrevista fue necesario partir de la construcción de categorías conceptuales: dispositivo y subjetivación; posteriormente, desde ambas analicé los relatos de experiencia obtenidos, de los que emergió una nueva categoría interpretativa: saberes híbridos, que en el decir de las maestras sobre la lectura, expresan una subjetividad que funciona como el andamiaje para saber-se y reconocer-se lectoras.

Dar voz las maestras, pasar su oralidad a relatos escritos con los que se construyó un trabajo de investigación y el presente artículo, me brindó la posibilidad de desbloquear el saber sometido de la lectura, al quedar sus relatos plasmados mediante la escritura para ser leídos se les permite jugar con la lógica derivada de los saberes dominantes, o bien, como lo expresa Collado "lo oral revela la complejidad de lo real, introduce lo irracional donde el documento escrito racionaliza o establece lógicas derivadas de una cultura dominante, ideologías que tal vez no han permeado en su totalidad la experiencia cotidiana" (2006: 21).

Siete relatos de maestras frente a grupo sirvieron como referente empírico; todas ellas reúnen características comunes que fueron los criterios para la selección de la muestra:

a) Disposición

b) Maestras Normalistas

c) Trabajar en educación primaria con grupo

d) Ejercer como maestra desde los 80

e) Ejercer como maestra desde los 90

Cabe aclarar que para el artículo solo se retoman tres relatos de siete que integraron la muestra. 


\section{DESARROLLO}

\section{Lectura y Comprensión: una mirada retrospectiva}

Al reflexionar sobre mi concepción de lectura, me escucho años atrás refiriéndome a ella como comprensión lectora, escucho a mis compańeros maestros y maestras, rememoro algunos cursos de actualización, me detengo y observo que el concepto comprensión está allí, como si siempre hubiera existido. No se le interroga en la actualidad ni en la historia de la lectura, se hace presente en una línea del tiempo, en una sucesión de fechas importantes que responden al progreso, al avance de una sociedad, pero se ignora el entramado de prácticas que se construyen en su historia, prácticas que implican saberes que se vuelven dominantes y permean en el sujeto con su uso. El sujeto portador de un saber dominante se hace partícipe de la distribución y la sumisión del saber.

Mi mirada a esa historia de la lectura de bloques conformados por un gran número de fechas me lleva a reconocer que la comprensión lectora es una construcción de la escuela moderna, ${ }^{9}$ otro invento reciente, como lo comenta Martínez Boom y Narodowski (1997: 7), un dispositivo de la modernidad, con una novedad de alrededor de un poco más de dos siglos; la escuela moderna se conformó como un espacio institucional cuyo principal objetivo fue deslindarse del discurso religioso para emerger como una institución del Estado. El deslinde fue progresivo, comenzó reagrupando y organizando prácticas de enseñanza dispersas hasta el siglo XVIII; este reagrupamiento implicó la selección, la normalización, la jerarquización y centralización de los saberes, ${ }^{10}$ lo que repercutió en desechar el falso saber y el no saber, que en la actualidad se expresa por medio de la organización de los sistemas

\footnotetext{
${ }^{9}$ Foucault analiza la Modernidad atribuyendo al término cinco sentidos, de acuerdo con Castro (2011: 316); en el caso, utilizo dos, por un lado, desde el libro Las palabras y las cosas en el que pensarla implica entenderla como un periodo histórico que se relaciona con un punto de vista epistémico que comienza hacia finales del siglo XVIII y se extiende hasta nuestros días, y desde el texto ¿Qué es la Ilustración?, el cual nos invita a pensar el término no como un periodo histórico, sino como una actitud: "Por actitud quiero decir un modo de relación con respecto a la actualidad, una elección voluntaria efectuada por algunos, así como una manera de obrar y de conducirse que, a la vez, marca una pertenencia y se presenta como una tarea" (Foucault, 2010: 981).

${ }^{10}$ Para Foucault (1997/2002: 170) antes del siglo XVIII había saberes, pero uno como disciplina no existía. Había ciencias y también estaba la filosofía, según Foucault.
} 
educativos modernos. Por ende, la lectura como saber entró al orden escolar, y su construcción como comprensión fue bajo los mismos elementos ${ }^{11}$ en que se fue estableciendo como institución del Estado, primero bajo el sostén de lo que Pineau (2010) llama matriz eclesiástica, en un segundo momento la lectura es objeto de discusión en los métodos de enseñanza, en tercer lugar se desplaza como objeto de la psicología y por último su domino se fortalece con la práctica de la evaluación.

\section{MATRIZ ECLESIÁSTICA, UNA BASE PARA LA CONSTRUCCIÓN DE LA LECTURA COMO COMPRENSIÓN}

\section{Reagrupar y ordenar el saber de la lectura (el control de un saber) no se impuso de un día para otro cuando la escuela se desligó de} lo religioso para inscribirse en el ámbito dominado por el Estado; un desligue aparente, con diversas resistencias, rodean a este saber. Durante la Colonia, se puso en práctica desde los intereses de la iglesia católica, cuyos miembros (frailes franciscanos, agustinos, dominicos y jesuitas) tomaron en sus manos la tarea de educar a los colonizados, con el propósito principal de la evangelización para implantar la religión católica; estos frailes traían

\footnotetext{
${ }^{11}$ Pineau (2010) en el artículo "¿Por qué triunfó la escuela?", se refiere a esta como a una de las mayores construcciones de la modernidad que responde a ciertas particularidades o elementos que provocan rupturas en el devenir histórico-educativo; tales elementos o piezas se fueron ensamblando para generar la escuela y reordenar a los saberes pedagógicos. Estas piezas son: a) la homología entre la escolarización y otros procesos educativos, b) la matriz eclesiástica, c) la regularización artificial, d) el uso específico del espacio y el tiempo, e) la pertenencia a un sistema mayor, f) la condición de fenómeno colectivo, g) la constitución del campo pedagógico y su reducción a lo escolar, h) la formación de un cuerpo de especialistas dotados de tecnologías específicas, i) el docente como ejemplo de conducta, j) una especial definición de infancia, k) el establecimiento de una relación inmodificable asimétrica entre docente y alumno, l) la generación de dispositivos específicos de disciplinamiento, m) la conformación de currículos y prácticas universales y uniformes, n) el ordenamiento de los contenidos, ñ) la descontextualización del contenido académico y creación del contenido escolar, o) la creación de sistemas de acreditación, sanción y evaluación escolar, y p) la generación de una oferta y demanda impresa específica. Considero que la lectura como comprensión es un saber que se fue ordenando, distribuyendo, a la par de la escuela, entre sus rupturas y continuidades y, por lo tanto, se teje con las mismas piezas propuestas por Pablo Pineau; sin embargo, realizo el análisis de su construcción desde solo tres elementos: a) matriz curricular; b) la lectura, como una cuestión de métodos que en el caso del análisis de Pablo Pineau, en el elemento Constitución del campo pedagógico y su reducción a lo escolar, afirma la idea de cómo enseñar termina reducida a lo curricular, y la lectura no es la excepción; c) la evaluación, que Pineau analiza con el elemento: creación de sistemas de acreditación, sanción y evaluación.
} 
consigo un saber adquirido desde la Edad Media, un saber de discontinuidades, principalmente con la Grecia clásica donde, según Cavallo y Chartier (2011: 43), la lectura tenía lugar más que nada en jardines y cobertizos y fue sustituida en la Edad Media por los espacios cerrados de las iglesias, las celdas, los refectorios, los claustros y las escuelas religiosas.

Así, la lectura pasa a ser una actividad de encierro, en el interior de un convento, para tener conocimiento de Dios y para la salvación del alma, para lo cual ciertas lecturas habían de ser entendidas, pensadas y hasta memorizadas. En la época Colonial, "los frailes daban clases de catecismo a los niños y niñas indios, a quienes reunían en el atrio de cada convento por la mañana" (Escalante, 2010: 32); sin embargo, este modo de leer se estableció con algunas limitaciones: mientras en Europa, después de la memorización, se invitaba a una lectura meditada, en la Nueva España la enseñanza recayó específicamente en la memorización y la recitación, usaron el saber de la lectura del conquistado -las imágenes- como instrumento para que el "indígena o indio", como fueron llamados, se adaptara y se acomodara ${ }^{12}$ a una realidad que le era impuesta por medio de la evangelización y no como el recurso que les permitiría el acto de encontrarse en el mundo y con él. ${ }^{13}$

Leer como memorización y recitación de textos religiosos dentro de un lugar cerrado fue una práctica que se desplazó y reforzó en la escuela gobernada por el Estado bajo los principios de la libertad, la igualdad y el progreso; espacio y saber bajo una misma matriz eclesiástica:

El mismo sistema de relevos y transformaciones que une a la mazmorra con la cárcel moderna une al monasterio con la escuela. En ambos casos, el espacio educativo se construye a partir de su cerrazón y separación

\footnotetext{
${ }^{12}$ Hago la lectura de adaptación y acomodación desde Paulo Freire, que en su libro $\mathrm{La}$ educación como práctica de la libertad explica que el Hombre se integra a las condiciones de su contexto; para él, la integración resulta de la capacidad de ajustarse a la realidad más que la de transformarla, que se une a la capacidad de optar, pero cuando el hombre pierde esta capacidad y se somete a prescripciones ajenas que lo minimizan, sus decisiones ya no son propias porque resultan de mandatos extraños, ya no se integra, solo se acomoda y se ajusta (Freire, 1969/1990: 31).

${ }^{13} \mathrm{La}$ enseñanza de la lectura en la Nueva España se realizó entre cartillas, silabarios y libros de devoción mediante la memorización y la repetición del catecismo.
} 
tajante del espacio mundano, separación que se justifica en una función de conservación de saber validado de la época, y que emparenta a ambas instituciones a su vez con el templo antiguo (Pineau, 2010: 31).

Reconocer como base a una matriz eclesiástica me permite mirar a la memorización como un modo de leer ${ }^{14}$ bajo un tipo de materiales, de los que podría mencionar a las cartillas ${ }^{15}$ que se usaron en la Nueva Espańa y se prolongaron, con modificaciones, a la escuela moderna; es decir, los relevos no solo son el espacio, la práctica lectora, sino también ciertos principios pedagógicos que se prolongan bajo la misma matriz para conformar sujetos que conllevan un tipo de pensamiento; por ejemplo, la siguiente afirmación de Bermúdez remite a un sujeto que ha sido permeado por ese saber de la lectura impuesto desde la Colonia, un saber que le dice que la lectura solo es leer y releer, memorizar y repetir: "Leer y releer los textos de la época; da la impresión de que quienes aprendían a leer lo hacían para memorizar: no era necesario comprender el contenido de la lectura: simplemente se leía, memorizaba y repetía” (2010: 129).

La cita muestra un claro efecto de que el saber dominante ejerce y provoca efectos en las acciones, discursos, formas de pensar y vivir en el mundo, de manera individual y colectiva; es el resultante de un sujeto que a través del tiempo no ha tenido la posibilidad de encontrarse con otros modos de decir la lectura y si por cuenta propia los tiene, los oculta, se somete a lo instituido. ¿Acaso no hay aquí un claro ejemplo de una tecnología del poder?, tecnología que además del cuerpo, llegó al alma del conquistado y después escolarizado.

\footnotetext{
${ }^{14} \mathrm{Al}$ utilizar el enunciado modos de leer me refiero al ¿cómo leer?, un cómo que es impuesto desde la reglas que dictan las instituciones sobre el qué leer, cómo leer (los comportamientos de los lectores); sin embargo, de acuerdo con Petrucci (2011: 445), ante un orden de la lectura siempre se contraponen prácticas libres, independientes y no reglamentadas.

15 "La Cartilla era un librito de unos diez por quince centímetros y de pocas páginas (16 hojas). En la época de los Reyes Católicos se publicó la primera cartilla y en 1542 se imprimió otra que siguió en uso por más de dos siglos y medio, hasta principios del XIX" (Tanck de Estrada, 2010: 50); sin embargo, las palabras no solo se quedan en el aire o en los discursos, sino que penetran el cuerpo y se quedan en el lenguaje como huellas difíciles de borrar. A pesar de que en la etapa de la Ilustración, motivados por la razón, la lógica y el orden modificaron el método de deletreo por el silabeo, titularon sus materiales Nueva cartilla.
} 
Entre el relevo y la transformación de la matriz eclesiástica también está lo excluido y lo sometido, como el sujeto conquistado y su saber. ¿Qué sucedió con el saber del colonizado tras la imposición de una nueva forma de leer?, en la imposición de un nuevo saber, solo se usó la materialidad del saber del conquistado. Cuando los frailes observaron que estos realizaban una lectura de imágenes, utilizaron este recurso en las cartillas para evangelizar, además de jeroglíficos y danzas. Los mexicas tenían una historia de lectura con jeroglíficos en el calmécac ${ }^{16}$-la escuela de élite-, un saber leer que adquirían los futuros gobernantes del pueblo o aquellos que se dedicaban al sacerdocio; curiosamente, la memorización no era el recurso que utilizaron para leer. Según Escalante (2010: 18), siguiendo la historia general de Sahagún, comentan que los jóvenes recluidos en el calmécac debían ocuparse del amoxtli ${ }^{17}$ y de la tlacuiolli ${ }^{18}$ e interpretar tres tipos de libros: el tanálamatl, el xiuhámatl y el de los sueños, que posterior a su interpretación utilizaban para integrarse a su comunidad:

Lo que se aprendía en el calmécac era, sobre todo, a comprender lo que decían esos libros. Los jóvenes que se integraran al sacerdocio, una vez concluida su instrucción, tendrían que utilizar con frecuencia los calendarios, del mismo modo que aquellos que se integraran a la administración y el gobierno necesitarían manejar los anales, dictar su contenido, incluso, y consultar otros libros [...] los catastrales, cartográficos y los tributarios (ibid., 2010: 19).

Enriquecían este modo de leer con la retórica; se adueñaban de la palabra, la hacían suya para elaborar discursos que pronunciaban en la escena política, en las relaciones familiares, en la comunicación de los viejos con los jóvenes, de los capitanes con la

\footnotetext{
${ }^{16}$ Cuatro fueron las instituciones de enseñanza e internación de los nahuas: telpochcalli, literalmente "casa de jóvenes"; calmécac, que significa "linaje de la casa"; cuicalli, "casa de canto" e ichpuchcalli, o "casa de doncellas". Escalante (2010: 13) comenta "Casi todo lo que sabemos sobre educación en la etapa anterior a la conquista española procede de las obras escritas en el siglo XVI por los frailes evangelizadores y por los indígenas que colaboraban con ellos o redactaban sus propias crónicas", por lo tanto, agrega que solo es posible ofrecer un panorama completo de la educación entre los nahuas del centro de México, donde se concentraron más las indagaciones, las fuentes y también los experimentos educativos coloniales.

${ }^{17}$ Del códice, del libro.

${ }^{18}$ Arte pictográfico.
} 
tropa, de los sacerdotes con el pueblo; era una cultura oral, a la que se le impuso una verdad de cómo, qué y para qué leer que los silenció para dejarlos fuera de su mundo, cuando a manera de prescripción, de receta, tuvieron que reducir la palabra a una mera recitación de palabras sin sentido, palabras vacías, adoptando un yo que no les pertenecía, construyendo una nueva subjetividad; sin embargo, y a manera de especulación, muchos de los conquistados no se ajustaron ni se adaptaron a la realidad que se les presentó, y tal vez, aquellos que habían aprendido en el calmécac a leer, aquellos grandes oradores, fueron los que en cuanto dominaron la lectura y la escritura del colonizador hicieron uso de ella para defender antiguos privilegios o para protestar por los malos tratos de los conquistadores, e incluso, para intervenir en favor del clero secular; intentaron dar a conocer un para qué leer opuesto al de la evangelización.

La verdad impuesta: modos de decir la lectura, de pensarla y ejercerla se desplazaron de la Colonia a la modernidad sobre la base de la matriz eclesiástica; cuando la escuela pública, gratuita y laica cobró fuerza, se vio influida por una filosofía liberal que poco transformó a la lectura como saber; sin embargo, en el siglo XIX, la filosofía positivista trasformó este saber al pensarse desde los métodos pedagógicos. El método es el segundo elemento sobre el cual la comprensión lectora encuentra bases para conformarse como concepto.

\section{LA LECTURA: DE LOS MÉTODOS PEDAGÓGICOS A LA PSICOLOGÍA EDUCATIVA}

La filosofía liberal se hizo presente en el periodo de la Independencia, en el que la educación se caracteriza más por un forcejeo entre Liberales y Conservadores, ${ }^{19}$ entre Estado e Iglesia;

\footnotetext{
${ }^{19}$ A principios del siglo XVIII la preocupación de instituir un sistema de enseñanza en manos del Estado dio origen a una serie de reformas educativas entre un ir y venir de gobiernos conservadores y liberales; Meneses (2001, en Ruíz-Ramírez, 2013) ha llamado a esas reformas ensayos; de acuerdo con el autor, son 12 momentos o ensayos educativos en los que los gobernantes en turno intentaron organizar la educación del país; de acuerdo con Ruíz-Ramírez (2013: 6), Meneses usa el término para denotar el hecho de que muchos de esos ensayos no llegaron a implementarse debido a la inestabilidad política existente en el país. De Iturbide hasta Benito Juárez; el forcejo recayó en el interés de que la educación fuera controlada por el Estado, además del debate de la libertad de enseñanza que muchas veces
} 
siguiendo a Zuluaga y Martínez-Boom, "en el forcejeo entre Estado e Iglesia, entre poder moral y poder político, entre intereses nacionales e intereses locales se producen modos de adecuación y apropiación del saber pedagógico como también de otros saberes" (1997: 66). La lectura, en la primera mitad del siglo XVIII, se ve influida y se adecua al discurso liberal que inscribe al sujeto como un ciudadano portador de derechos y obligaciones; la escuela lancasterian ${ }^{20}$ respondió a estos principios, pero además fue una propuesta, resultado de la conciliación entre políticos, escritores y clérigos, en que el sistema lancasteriano reduciría el analfabetismo entre otros temas que les inquietaban:

Tres temas les inquietaban: transferir el sentimiento de lealtad de la figura paterna del rey al concepto abstracto de Estado moderno; convertir a la siguiente generación de jóvenes en buenos ciudadanos, conscientes de sus obligaciones hacia el Estado, y formar obreros calificados y responsables (Staples, 2010: 105).

En la etapa liberal, de la mano de la enseñanza mutua y la cartilla lancasteriana, la lectura respondió a las exigencias de la cobertura educativa; saber leer ya no respondió a la memorización de oraciones para apropiarse de la religión cristiana, y su principio de gobernabilidad de un sujeto evangelizado se desplazó con este sistema a un sujeto disciplinado, es lo que Pineau (2010:36) reconoce como la generación de dispositivos específicos de disciplinamiento -la construcción de cuerpos dóciles-, bajo la homogeneización de un saber.

Ya avanzado la mitad del siglo XVIII y principios del XIX, la lectura se vuelve objeto de los métodos pedagógicos; ${ }^{21}$ se le

era aprovechado para seguir enseñando catecismo en las escuelas de la mano de valores cívicos y morales. Sobre la historia de la educación en México se puede consultar los libros Historia de la Educación en México (1876-1976), Historia mínima. La educación en México y El positivismo en México: nacimiento, apogeo y decadencia.

${ }^{20} \mathrm{La}$ escuela lancasteriana se estableció en la ciudad de México a partir de 1822, en 1842, el gobierno central le confió la Dirección General de Instrucción Primaria para todo el país; Staples (2010: 105) afirma que fue el inicio de una auténtica centralización educativa, de un manual para maestros único y obligatorio y de una docencia rigurosamente uniforme, por lo menos en teoría. Esta afirmación es un ejemplo de la conformación no solo de un saber homogéneo sino también de sujetos.

${ }^{21}$ De acuerdo con Bazant (2010: 209), la importancia que cobra el uso del método de enseñanza en el siglo XIX, en México, provino del suizo Johann Heinrich Pestalozzi: "La en- 
discute como una operación observable por lo que entra a los principios de cientificidad: observación y experimentación, resultado de la influencia de la filosofía positivista; métodos como el racional de la lectura, ${ }^{22}$ el fonético, ${ }^{23}$ el onomatopéyico ${ }^{24}$ compartieron sus bases bajo el orden de una serie de pasos que iban de lo simple a lo complejo, o de lo concreto a lo abstracto; el uso en la escuela de cualquiera de estos métodos superaba la crítica de que se enseńaran reglas abstractas antes que ejemplos, máximas antes que experiencias, definiciones antes que objetos; la escuela y el saber de la lectura a partir del método responden a una enseñanza basada en la objetividad por la cual los alumnos alcanzarían los resultados pedagógicos esperados.

Al parecer, superar la lectura de memorización no se logró con el uso de los métodos pedagógicos basados en la enseñanza objetiva, ni con los que encontraron sustento en la escuela nueva; pasados ya muchos ańos, entre 1970 y 1976, en México se da la presencia de otra reforma educativa, en la que se manifestó la preocupación por la memorización, así que se propuso, para la adquisición de la lectura y la escritura, el método global de análisis estructural: "El nuevo método se basa en la premisa de que leer es comprender la lengua escrita; por lo tanto la lectura no debe reducirse únicamente al descifrado de signos, ni la escritura a la reproducción de trazos gráficos" (Greaves, 2010: 347).

En apariencia, el discurso se reproduce y las acciones también; hay ausencia de comprensión y para lograrla se recurre a

señanza debía tener un orden y método cuyo desarrollo debía ser paralelo a la evolución psíquica y física del hombre. El método objetivo o intuitivo de Pestalozzi pretendía educar al niño por medio de la observación de los objetos materiales", con la premisa de la observación y la objetividad procuró que se desarrollaran conjuntamente la observación, la atención, la percepción, la memoria y la imaginación -la imaginación a partir de la observación-, la enseñanza ya no recaía solo en la memorización.

${ }^{22}$ Antonio de P. Castilla publicó el Método racional de lectura que seguía cinco pasos: oral, repetición y analítico, imitación o copia de los signos, reminiscencia, y acción o movimiento

${ }^{23} \mathrm{El}$ método de Rébsamen, publicado por primera vez en 1889 , fue el fonético que suplantó al método de deletreo por medio de la marcha analítica-sintética: la marcha analítica es aquella que descompone todo en sus partes, estudiando primero aquel y luego estas, en orden siempre decreciente. La marcha sintética procede a la inversa de la analítica: presenta al alumno primero las partes y luego las reúne para formar el todo. (Castellanos, 1912: 179-182, en Bazant, 2010: 233).

${ }^{24}$ Llamado también Torres Quintero por ser su creador, y consistía en el fonetismo onomatopéyico: deducción de los sonidos de las letras de algún fenómeno físico producido por el hombre, los animales o las cosas. 
los métodos, un siglo antes, al método onomatopéyico o fonético, un siglo después al de análisis estructural; pero en el fondo no hay una discusión de qué tipo de lectores se quiere formar, para qué y desde dónde, mucho menos se interroga qué es leer, ni por qué discutir la lectura desde los métodos pedagógicos; sin embargo, en estos ańos se comienza a usar en el discurso el concepto de comprensión lectora-leer es comprender-, y en el cambio de concepto está implícito el desplazamiento de la pedagogía a la psicología. Así la lectura comienza un recorrido que va de la psicología diferencial a la cognitiva, disciplinas que la definen como un proceso cognitivo, en el cual el sujeto lector es el responsable de comprender, y por lo tanto es él el observado, calificado, medido en y por la escuela. La lectura ya no es el objeto del método; en su transición a la psicología ahora el objeto es el sujeto sometido a un saber de la lectura que se ha construido desde la ciencia. La comprensión lectora queda establecida como un saber sobre una verdad-demostración, verdad que se produce desde el discurso científico que supone, de acuerdo con Foucault (2005: 236-242), que existe por todas partes, en todo instante, que cualquier persona dotada de los instrumentos necesarios puede descubrir y acceder a ella. En el caso de la lectura será desde el uso de los test, posteriormente, evaluación, que encontrará su demostración, como veremos enseguida.

\section{Y COMENZAMOS A HABLAR DE COMPRENSIÓN LECTORA}

A partir de la década de los setenta, en México se comienza hablar de comprensión lectora, como se manifiesta en la última cita del apartado anterior; hasta la fecha, programas de estudio, maestros, medios de comunicación, evaluaciones estandarizadas incorporaron en su lenguaje a la lectura como comprensión.

La lectura de comprensión es una invención reciente, que integró su estructura teórico-conceptual, primero desde la psicología diferencial que utiliza instrumentos de los que se obtiene información cuantitativa para determinar diferencias individuales; por ejemplo, una comprensión defectuosa o inexistente era lo que ponían de manifiesto las investigaciones de Thorndike. 
(1917). ${ }^{25}$ Por otro lado, los trabajos de Bartlett (1932) sobre la memoria han influido en la importancia que se da al uso de los conocimientos previos para comprender un texto (Solé, 2001: 21). De acuerdo con Solé (2001), tanto Thorndike como Bartlett son nombres importantes en el cambio de orientación; por un lado, tener en cuenta la comprensión y, por otro, dirigir los esfuerzos de la investigación a objetivos más prácticos y aplicados; sin embargo, cuando en México surge la necesidad de desarrollar la comprensión en el aula, en Estados Unidos ya se había conformado un marco teórico de base psicológica, que inició aproximadamente en la década de los veinte ${ }^{26}$ con el conductismo, y ya en los setenta la comprensión era estudiada pero desde la psicología cognitiva y la psicolingüística.

La lectura como saber y construcción de la psicolingüística, en México, comenzó a hacerse presente en la década de los noventa, como un proceso interactivo y constructivo:

La relativa capacidad de un lector en particular es obviamente importante para el uso exitoso del proceso. Pero también lo es el propósito del lector, la cultura social, el conocimiento previo, el control lingüístico, las actitudes y los esquemas conceptuales. Toda lectura es una interpretación y lo que el lector es capaz de comprender y de aprender a través de la lectura depende fuertemente de lo que el lector conoce y cree antes de la lectura. Diferentes personas leyendo el mismo texto variarán en lo que comprenden de él, según sus contribuciones personales al significado (Goodman, 1994: 18).

Los libros de texto de español de 1993, utilizados hasta 2009, recibieron importantes contribuciones de esta perspectiva sobre la lectura, principalmente sobre sus estrategias, ${ }^{27}$ que para

\footnotetext{
${ }^{25}$ Thorndike realizó estudios de focalización de vocabulario, utilizó listas de palabras basadas en estudios de frecuencias de palabras.

${ }^{26}$ De acuerdo con Goodman (1994: 14): "La educación en Estados Unidos en los años 20 creía con gran optimismo que la ciencia proveería soluciones para todos los problemas educativos, incluyendo la alfabetización universal. Este -cientismo- coincidió con el surgimiento del conductismo en psicología y el empirismo lógico en filosofía. Especificidad, secuencia y cuantificación se convirtieron en las palabras claves de la educación norteamericana".

${ }^{27}$ Siguiendo a Goodman: "Muestreo: los lectores desarrollan estrategias de muestreo. El texto provee índices redundantes que no son igualmente útiles. El lector debe seleccionar de estos índices solamente aquellos que son más útiles. Predicción: los lectores son capaces de anticipar el texto. Pueden utilizar estrategias de predicción para prever el final de una historia, la lógica de una explicación, la estructura de una oración compleja y el final de una
} 
Goodman (1994) son indispensables en este proceso: muestreo, predicción, inferencia y la autocorrección; el libro del maestro de primer grado a sexto las hizo presentes como sugerencias para trabajarla en el aula.

En lo escrito hasta aquí reconozco que en el desplazamiento del saber de la lectura que va de la prioridad del uso de métodos pedagógicos para el aprestamiento de la lectura, hacia el uso de instrumentos cuantitativos de la piscología, transición que da paso al uso del concepto comprensión lectora, se encuentra la presencia del eco positivista como postura epistemológica que permeó y estableció sus bases, no solo en la enseñanza objetiva que dominó gran parte del modelo educativo mexicano a partir de la Restauración de la República, hasta el Porfiriato, sino también en los inicios de la psicología educativa, pero ahora desde el conductismo y el asociacionismo. En la psicología cognitiva, con un influjo racionalista.

La influencia de una postura con base en el discurso de la ciencia empirista y racionalista conformó una verdad sobre la lectura que a través del tiempo se ha impuesto desde la conformación de la escuela como institución; una verdad que nos permea como maestros y determina nuestra voluntad de saber. Verdad que influye en nuestro lenguaje, en cómo decimos las cosas y nos apropiamos de los saberes para llevarlos a la práctica; saberes dominantes y homogéneos; por ejemplo en algunos relatos, ${ }^{28}$ las maestras suelen hablar de método onomatopéyico, ecléctico; conceptos como estrategia lectora, del que se desprende la inferencia o el uso de conocimientos previos, han trastocado sus palabras, bajo las que toman una postura ya sea favorable o desfavorable para contar sus prácticas; como ejemplo tomo el fragmento del relato de la maestra Pamela, frente a grupo, que ha trabajado con tres reformas educativas, para comentar sobre su postura ante el modo en que se evalúa la lectura en las aulas con el Manual de

palabra. Inferencia: es un medio poderoso por el cual las personas complementan la información disponible utilizando el conocimiento conceptual y lingüístico y los esquemas que ya poseen. Autocorrección: los lectores deben también tener estrategias de autocorrección para reconsiderar la información que tienen u obtener más información cuando no pueden confirmar sus expectativas" (1994: 21).

${ }^{28}$ Los fragmentos de relatos aquí expuestos responden a la Metodología de Historia Oral de la tesis de investigación realizada en el ISCEEM. 


\section{procedimientos para el fomento y la valoración de la competencia lectora; ella, me cuenta:}

Yo siento que de esa manera el niño no te puede dar una o no puedes obtener un resultado real, porque hay niños memorísticos; entonces en algunas de las preguntas que supuestamente sí hay una interpretación, en una de ellas, por ejemplo, hay inferencia, me parece que era en la tercera, por ejemplo, en la de los burros de Don Tomás, te planteaba “¿por qué crees tú que él decía que eran tres y eran cuatro?”. Eso no lo alcanzaban a determinar los chicos, casi nadie contestaba correctamente esa pregunta y luego, cuando te planteaban "ahora cuéntame tú la historia", había niños memorísticos que te la decían así "ta ta ta”, pero no sabían inferir, no sabían ni por qué estaba sucediendo, vamos, no había una relación, una profundidad con respecto a la lectura; y les preguntabas después, “¿qué aprendiste tú de eso?”, tampoco inferían eso. Entonces, yo creo que eso no era la lectura de comprensión. A mí, la verdad, el manual, sí siento que fue muy impositivo y siento también que fue sin un fundamento congruente con la modernidad o congruente con la nueva reforma [o sea] totalmente desfasado; que sí, a lo mejor tenía algunos aspectos positivos, porque sí los tenía.

La maestra Pamela conversa sobre su gusto de trabajar la lectura en el aula, que tiene que ver con la modificación del enfoque formalista de español al comunicativo funcional; opta por el segundo, que incluye estrategias lectoras. Ella me comenta cómo trabaja la lectura en el aula:

Pues, por ejemplo, haciéndoles la entonación, las audiciones lectoras, que ellos hagan inferencias, predicciones, el muestreo, todo eso, estrategias que no aprendí en la Normal; déjame decirte, yo fui de otras generaciones, te digo que salimos con esto [me enseńa un examen], he ido aprendiendo a través de la marcha y ahorita, creo que fue en el noventa y tantos, cuando nos mandaron esos libritos; creo que eran auxiliares para el maestro, con los ficheros y todo eso, que fue cuando se empezó a despertar más las estrategias y las actividades para los alumnos, para enfocarlos a la lectura, fue que empecé a aprender. ${ }^{29}$

\footnotetext{
${ }^{29}$ Entrevista a la maestra "Pamela", Tlalnepantla, México, 10 de noviembre de 2013.
} 
La maestra Laura, cuando habla de comprensión lectora, reconoce ser ecléctica; pero además, usa los conceptos estrategias lectoras y metacomprensión, ambos se pusieron en circulación con la Reforma Educativa de 1993:

Como a mí me gusta ser muy ecléctica, combiné un poquito de lo de las estrategias de lectura, que son las de 1993, que me parecen muy bien porque ahí hay una prelectura, una lectura y una postlectura; ahí empiezas a llegar a eso, a la metacomprensión del texto y, como al principio también vas a invertirle tiempo; sin embargo, es mucho más benéfico el tiempo que le vas invertir a eso que a estar tomando la lectura de velocidad; definitivamente no, y combiné. Cuando al año vi que no me era funcional la aplicación tal cual es el manual, combiné y empecé aplicar las estrategias de lectura. ${ }^{30}$

Las maestras se han apropiado de una verdad que se refuerza cuando la evaluación de la lectura se pone en circulación y funcionamiento desde otra práctica; esta promueve una serie de discursos sobre la importancia de leer, de fomentar y valorarla, más aún en una sociedad obsesionada por evaluar de manera estandarizada, que busca lo medible, cuantificable para interpretar la realidad de manera objetiva; quiero hacer notar que la comprensión lectora surge con la etapa del test, con el uso de instrumentos que evalúan el desempeño de un sujeto en busca del significado de un texto. Ha impactado en el sujeto maestro, considerándola necesaria, como lo comenta la maestra Lidia:

No Paty, creo que sí la tenemos que evaluar, puesto que nosotros damos un referente a los padres de los logros y necesidades de los nińos, sobre todo ahora con la cartilla, se nos pide que hagamos sugerencias, que sepamos el nivel sobre el desarrollo del niño. Sí es importante que la evaluemos, pero no que la encasillemos en un solo material, como es el manual, o con registros que se reportan, pero no sabemos qué pasa con ellos y que, además, pretenda evaluar la comprensión con cuatro preguntas. Es importante que en cualquier grado nos hablen de los detalles de la lectura, pero también los niños deben ser capaces de expresar otros sentimientos sobre lo que leen o lo que identifican en un personaje, ¿si?, que me digan los personajes del

\footnotetext{
${ }^{30}$ Entrevista a la maestra "Laura", Tlalnepantla, México, 2 de diciembre de 2013.
} 
cuento o el tema de una lectura, pero que también me digan por qué les gustó o les disgustó o qué harían en el caso de un personaje. ${ }^{31}$

La evaluación en la actualidad juega un papel estelar en el currículo mexicano, "se ha diseñado un currículo a medida de las pruebas, un traje a su medida, una reforma (al vapor) de planes, programas y libros, centrados en el concepto competencia", afirma el investigador veracruzano Jorge Vaca (Vaca et al., 2011: 58). Agregaría, que además de planes, programas y libros de texto, ENLACE y el Manual de procedimientos para el fomento y la valoración de la competencia lectora, al que me he referido como manual, se alinean a PISA y disponen de la lectura como una habilidad o un conjunto de habilidades que la evaluación distribuye, selecciona y omite otros saberes de lectura; considerarla capacidad o habilidad es necesario para la evaluación, otros saberes no podrían entrar en esta práctica, desde otras posturas la lectura no es evaluable.

En apariencia, ya no se habla de comprensión lectora, se ha sustituido por competencia lectora; pocas son las diferencias, la comprensión sigue siendo el concepto estelar y el sujeto lector su principal objeto de estudio: "La competencia lectora es la capacidad de un individuo para comprender, emplear, reflexionar e interesarse en los textos escritos con el fin de lograr sus metas personales, desarrollar sus conocimientos, su potencial personal $y$, en consecuencia, participar en la sociedad" (INEE, 2010: 3).

Para no dejar cabos sueltos, retomo el hecho de que, cuando en nuestro país, en la década de los noventa, se intentó superar la comprensión que había conformado la psicología diferencial y se desplazó el concepto hacia la psicolingüística, ambas dan prioridad al proceso cognitivo del alumno para comprender, pero la psicolingüística hizo esfuerzos, principalmente, de incorporar los conocimientos previos del alumno, de no ubicar el proceso de lectura solo en lo individual; sin embargo, el desarrollo cognoscitivo del sujeto es determinante: "la perspectiva psicolingüística tiende hacia la concepción de un sujeto que aprende -a través de un proceso complejo, pero único y bastante autónomo- a encontrar sentido a los múltiples ejemplos de lengua escrita que

\footnotetext{
${ }^{31}$ Entrevista a la maestra "Lidia", Tlalnepantla, México, 4 de diciembre de 2013.
} 
se le presentan. El desarrollo cognoscitivo del sujeto parece determinar ciertas constantes en la apropiación de la lectoescritura independientes de las diferencias lingüísticas, culturales y del sistema de escritura" (Rockwell, 1994: 298). Recuperar el contexto, la historia, los condicionamientos sociales particulares ayudaría a desbloquear el saber dominante de la lectura, pero para dar oportunidad a los saberes sometidos es necesario reconocer que en cada momento histórico hay un mismo saber excluido que se subordinó a la verdad-demostración, que se manifiesta solo en determinados lugares y momentos, es el saber de la experiencia que se vincula con el de la subjetividad.

\section{LA EXPERIENCIA DE LA LECTURA: UN SABER SOMETIDO}

En el discurso dominante de la lectura, al que me he referido como el que proviene de los discursos de la ciencia, que hizo emerger una verdad-demostración al basar sus principios en lo observable, lo cuantificable y lo universal, no se da margen a la experiencia, que difiere de la experimentación. La experiencia de la que hablo es aquella en la que Larrosa (2007: 34) reconoce una implicación de la subjetividad "la experiencia es lo que nos pasa, o lo que nos acontece, o lo que nos llega. No lo que pasa, o lo que acontece, o lo que llega, sino lo que nos pasa, o nos acontece, o nos llega”. Ese "nos" que marca Larrosa me permite afirmar que la lectura, desde la experiencia, no permite una universal, sino una pluralidad de lecturas. El saber de la lectura sometido es del lector, parte de él, pasa por él; es su vivencia, su mirada, el golpe que da que pensar, se enfrenta a lo ya dado. Por ejemplo, en Kafka, se aprecia lo que podría significar una experiencia de la lectura:

En general, creo que solo debemos leer libros que muerdan y arańen. Si el libro que estamos leyendo no nos despierta como un golpe en el cráneo, ¿para qué molestarnos en leerlo? ¿Para que nos haga felices, como dices tú? Cielo santo, seríamos igual de felices si no tuviéramos ningún libro. Los libros que nos hacen felices también podríamos escribirlos nosotros mismos si no nos quedara otro remedio. Lo que necesitamos son libros que nos golpeen como una desgracia dolorosa, como la muerte de alguien a quien queríamos más que a nosotros mismos, libros que nos hagan 
sentirnos desterrados a los bosques más lejanos, lejos de toda presencia humana, como un suicidio. Un libro debe ser el hacha que quiebre el mar helado dentro de nosotros. Eso es lo que creo (Manguel, 2011: 159).

Lo que narra Kafka es una carta como respuesta a un amigo, refleja su vivencia de una época de lectura memorizada y es que la experiencia transcurre en el tiempo, tiene un claro contenido narrativo que se puede reclamar del relato vivido (Contreras y Pérez de Lara, 2010); el relato de Kafka, impregnado de vivencias e implicaciones subjetivas, es ejemplo de esos saberes de la lectura sometidos y sepultados en la lógica de los sistemas educativos.

Otro relato de experiencia lo encuentro en Paulo Freire; él da cuenta de tres momentos en el acto de leer: en el primero, el individuo efectúa una lectura previa de las cosas de su mundo, "la experiencia del mundo en el momento que aún no leía la palabra" -dice Freire-, es el mundo con ojos de nińo, que a su alrededor percibe la gama de colores, la diversidad de sonidos y sensaciones que lo invitan al juego, un mundo donde aparece la familia -los otros-, las historias que provocan miedo, alegría o llanto, los animales como el gato y el perro; un mundo en convivencia con él y los otros.

El segundo momento, se lleva a cabo con el aprestamiento de las palabras escritas, que para Freire fluyó naturalmente de la lectura del mundo particular; no hay un mundo ajeno, es el mundo del sujeto. Este segundo momento se contrapone con un ejemplo que Vaca y colaboradores (2011) comentan acerca de un texto de PISA 2000, que tiene el título de "La limpieza mecánica de las playas": Jorge Vaca dice "En México o, más aún, en Veracruz (donde hay playas), ni siquiera conocemos esas máquinas. Mucho menos hemos reflexionado sobre el impacto ecológico de su uso", es otro mundo el de las evaluaciones estandarizadas, no es el mundo de un sujeto particular, es la ruptura de un mundo. En Freire la lectura fluye porque, como afirma, "No era algo que estuviera superpuesto a él".

En el tercer momento, la lectura se prolonga en relectura y reescritura del mundo, que se enriquece de un tipo de lectura particular: la crítica, lectura en la que no hay espacio para la memorización: "Ejercicios de los que resultase un simple darnos cuenta de la existencia de una página escrita delante de nosotros 
que debía ser cadenciada, mecánica y fastidiosamente deletreada, en lugar de realmente leída" (Freire, 1988: 101); por el contrario, la lectura es como un objeto a desvelar, aprender su significación profunda, una lectura que transforme el mundo a través de nuestra práctica consciente.

La lectura del mundo, que con gran sensibilidad relata Freire, es un ejemplo de saber sometido, un saber que se encuentra en el relato de su propia vida: su niñez, juventud y vida profesional; no hay desarrollos teóricos, no hay investigación experimental para que Freire pueda hablar de la lectura, tampoco es la propuesta redentora que viene a mejorar la comprensión lectora; es el fragmento de la vida de un pedagogo que uno a los relatos de las maestras. El saber de todas ellas también se ubica entre los sometidos, pero híbridos cuando han conformado saberes no solo desde un punto de vista personal, de experiencia de vida, sino que se han mezclado con los promovidos en la escuela desde enfoques teóricos como el de la psicología.

Retomo el relato de la maestra Laura, su memoria e interés por hablar de la lectura la llevan a buscar en sus recuerdos de la niñez, el origen de su pasión por la narrativa:

Para mí leer es toda una aventura; para empezar, yo soy amantísima de la narrativa, cuento o novela porque me gusta echar a volar mi imaginación como inicio, ¿̨no?, y recordemos que así es como han surgido los grandes cimientos. Hace unas cuantas semanas estábamos platicando en casa sobre qué sería primero, todas las innovaciones científicas que ya hay o los libros de Julio Verne, cómo surgió en Julio Verne toda esa idea del submarino, del viaje a la luna, en fin, todo lo que ha manejado Julio Verne en sus libros o Isaac Asimov hace décadas, ¿̇no?, y lo que ahora estamos contemplando en la ciencia. Entonces la imaginación para mí es fundamental para empezar y después, cuando ya me aventuro a leer ensayos, libros ya informativos, científicos, tocantes a la educación, pues me ayudan a tener un parámetro y hacer un estudio y a analizar qué es lo que está sucediendo en mi sociedad, para entender más a mi sociedad. Entonces, leer también es una gran puerta al conocer mi sociedad, en donde me estoy moviendo y a mí misma. Fíjate que, en ese sentido, yo creo que siempre lo hemos discutido allá, en casa; de mis hermanos y yo, yo siempre he sido la más curiosa; luego me hace burla mi esposo porque 
me dice "sí, sí, tú que traducías a Borges a los ocho años", porque yo me aventuraba a leer, llegaban libros a mi casa, bueno a la de mi mamá y yo me aventuraba a leer desde los ocho años libros que quizás no eran para mi edad, porque antes, en aquella época, no teníamos la aventura de los Libros del rincón o de toda esa lectura infantil y juvenil que ahora conocemos; entonces, a mí me llegaron muchas lecturas tan pesadas, incluso como la de los hornos de Hitler que yo, asustada a los diez años, de plano cerré el libro porque sí me impactó muchísimo, y me acuerdo muy bien que eran los diez años porque precisamente empezábamos a ver las guerras mundiales en la primaria; entonces, a mí me impactó muchísimo... Y así, conocerme a mí misma, porque a través de conocer los referentes de otros personajes aprendí, he aprendido, a conocerme más a mí; Ana Frank, otra niña en la Segunda Guerra Mundial, coincidentemente, es del mismo día que yo, del 12 junio, y eso a mí me entusiasmó cuando a los diez años estaba leyendo el Diario de Ana Frank y mi identifiqué mucho con las necesidades de esa niña, de Ana Frank, y eso me permitió analizar cómo era yo, qué quería yo, y sí, créeme, que muy chavita. Otro libro que también me acuerdo en la secundaria, Los renglones torcidos de Dios; cómo me fascinó, a partir de ahí, la psicología, la psiquiatría, porque, qué puede haber en la mente humana o de qué manera se trastoca la mente humana que llega a esos niveles de indignidad, y así con cada uno de los libros; otro libro en que también aprendí a valorar la vida y la muerte, un libro que cómo he querido rescatar, fue Juegos prohibidos, de dos niñitos europeos de la guerra mundial que juegan a la muerte. Entonces, creo que ese lo leí cuando tenía nueve años, te digo, lecturas que nada que ver con mi edad. ${ }^{32}$

Cuando Freire narra su vuelta a la infancia para explicar el acto de leer, menciona esas conversaciones familiares que le provocaron miedo; el tema familiar eran las almas en pena, y el Freire niño se envolvía en miedo por la noche, esperando la madrugada semiclareada y con ella el canto de los pájaros, sus recuerdos con las palabras siempre rodeado de los otros, su maestra Eunice, de la que nos dice: "Con ella, la lectura de la palabra, de la frase, de la oración, jamás significó una ruptura con la 'lectura' del mundo" (Freire, 1988: 100).

La lectura de la maestra Laura también ha estado acompañada, primero de la familia materna y luego de su esposo e hija; cuando

\footnotetext{
${ }^{32}$ Entrevista a la maestra "Laura", Tlalnepantla, México, 2 de diciembre del 2013.
} 
me platica su identificación con Ana Frank, no solo por la coincidencia del día de cumpleaños, sino por las necesidades de esa niña, esas necesidades que no menciona, me permite ver su lectura del mundo, de su mundo, uno que no es el mío ni el de sus alumnos, que no responde a una lectura universal exigida por una evaluación; es la relación con el texto que la lleva a vivir su experiencia de la lectura, a pensar de un modo particular su relación con la lectura y sus alumnos. La maestra Laura guía a sus alumnos a pensar en ellos, en sus problemas y en el de los otros con la lectura.

Kafka, Paulo Freire y la maestra Laura, tres sujetos, cada uno en su tiempo, juegan con los saberes dominantes, hegemónicos, de la lectura para producir un saber que se aleja de conocimientos objetivos, válidos y universales, todos desde su ser y el ser con el mundo hablan de una lectura abierta, personal, una experiencia, su verdad, una verdad-acontecimiento que desplaza a la verdaddemostración, que da la posibilidad de transformar su ser sujeto $\mathrm{y}$ de pensar en los otros.

\section{PARA CERRAR}

He presentado algunos elementos que permiten mirar a la lectura como un saber que oscila de lo dominante a lo sometido en la práctica educativa y evaluadora; para reconocer tal oscilación fue necesario interrogar el concepto comprensión lectora como el saber dominante tanto en uso como en apropiación del discurso escolar; este concepto emerge en el siglo XIX desde la psicología diferencial, con la que toma forma de mensurable y objetivo. Con el tiempo, la comprensión lectora conformará espacios que dieron y dan lugar a otros modelos teóricos con la pretensión de validar el enunciado base -proceso cognitivo- desde el que se conformó como concepto y permitió la formación de otros, por ejemplo, los modelos estratégicos, interactivos o los que se refieren a la memoria operativa, todos ellos constitutivos del discurso científico de la piscología diferencial y la psicolingüística.

La comprensión lectora como saber dominante no es el resultado de la suma de verdades que se han ido estableciendo sobre la lectura a través del tiempo, sino un invento de la modernidad que sometió a otros saberes, como el de la experiencia-subjetividad, 
saber descalificado por no responder a los criterios formales de cientificidad que, a su vez, provocaron que quedara enmascarado por el de la experiencia-experimento, este último como el elemento del método que permite conocer y dominar la realidad presentada.

Sin embargo, la experiencia-subjetividad como saber sometido de la lectura puede ser reclamada desde las ficciones, reflexiones o bien desde el relato en la cotidianidad del aula; así, desde pequeños fragmentos de relatos, el saber sometido sale a la luz y se torna híbrido cuando el sujeto maestro toma posición para hablar de la lectura desde el concepto de la comprensión lectora pero también desde su experiencia -no la de la objetividad de los hechos-, la personal, la que tiene que ver con su sentir y su persona que emerge para enfrentar el dominio de un saber.

Son los saberes sometidos los que necesitamos desbloquear para encontrar otros sentidos a las prácticas educativas que no sean solo las de los saberes dominantes.

En el aula, en nuestra cotidianidad con los alumnos, podemos entablar una relación con la lectura que no se base exclusivamente en responder a la estructura del texto, a su apropiación; es importante generar una conversación con lo escrito que no interrogue solo al autor, no limitar la lectura a la búsqueda de la idea principal o a identificar quiénes son los personajes principales, la relación a la que me refiero, es la propuesta de Larrosa (2007), "la lectura como formación".

La lectura como formación nos permite una nueva relación con lo escrito, con el texto, una relación íntima con nuestra subjetividad que nos lleva a interrogar el sí mismo, nuestro ser para salir transformados. Este tipo de lectura invita al lector a escuchar para escuchar-se, mirar para mirar-se y al maestro en permitir que el texto sea una voz que hay que escuchar.

No hay lectura que analizar, no hay código que descifrar, no hay palabra que memorizar, no hay ni buenas ni malas lecturas, no hay mensaje oculto que descubrir, no hay lectura que explicar; lo que se requiere es una actitud de escucha atenta, por lo que el maestro debe dejar aprender al alumno, y ese dejar aprender, para Larrosa (2007: 46) "es un hacer que requiere humildad y silencio. Pero que también exige audacia y hablar alto porque para dejar aprender hay que eliminar muchos obstáculos. Entre ellos la arrogancia de los que saben". 
Por último, escuchemos el relato de Freire, Kafka y la maestra Laura; cada uno nos susurra su encuentro consigo mismos gracias a que establecieron una relación de escucha con la lectura.

\section{REFERENCIAS BIBLIOGRÁFICAS}

Alfaro, L. G., Comprender y vivir la lectura, México, UNAM, 2007. Bazant, M., "Lecturas del Porfiriato", en Historia de la lectura en México, México, D. F., COLMEX, 2010, pp. 205-242.

Bermúdez, M. T. "Las leyes, los libros de texto y la lectura, 1857-1876", en Historia de la lectura en México, México, D. F., COLMEX, 2010, pp. 127-152.

Castro, E., Diccionario Foucault. Temas, conceptos y autores, Argentina, Siglo Veintiuno, 2011.

Cavallo, G. y Chartier, R. Introducción, en: Historia de la lectura: en el mundo occidental, México, Taurus, 2011, pp. 25-65.

Collado, H. “¿Qué es la historia oral?”, en La historia micrófono, México, Instituto Mora, 2006, pp.13-32.

Contreras, J. y Pérez de Lara, N. Investigar la experiencia educativa, Madrid, Morata, 2010.

De Certeau, M. La invención de lo cotidiano I. Artes de hacer, México, Universidad Iberoamericana, 2010.

De la Fuente, R. E. "Diversidad y sumisión en los saberes”, en Tramas, vol. 27, 2007, pp. 129-141.

Escalante, G. P. La etapa indígena, en Historia minima, La educación en México, México, COLMEX, 2010, pp.13-35.

Foucault, M. Defender la Sociedad, México, Fondo de Cultura Económica, 1997/2002.

Foucault, M. El poder psiquiátrico. Curso del Collége de France (19731974), Buenos Aires, Fondo de Cultura Económica, 2005.

Foucault, M. Obras Esenciales, Buenos Aires, Paidós, 2010.

Freire, P. La educación como práctica de la libertad, México, D. F, Siglo XXI, 1969/1999.

Freire, P. La importancia de leer y el proceso de liberación, México, Siglo XXI, 1988.

Goodman, K. "El proceso de lectura: Consideraciones a través de las lenguas y del desarrollo", en Nuevas perspectivas sobre los procesos de lectura y escritura, México, Siglo XXI, 1994, pp. 13-28. 
Greaves, C. "La Secretaría de Educación Pública y la lectura”, en Historia de la lectura en México, México, D. F., COLMEX, 2010, pp. 338-371.

INEE. México en PISA 2009, México, D. F., INEE, 2010.

Larrosa, J. La experiencia de la lectura. Estudios sobre literatura y formación, México, Fondo de Cultura Económica, 2007. Manguel, A. Una historia de la lectura, México, Almadía, 2011.

Martínez Boom, A. y Narodowski, M. Escuela, Historia y Poder. Miradas desde América Latina, Buenos Aires, Ediciones Novedades Educativas, 1997.

Petrucci, A. "Leer por leer: un porvenir para la lectura", en: Historia de la lectura, México, Taurus, 2011, pp. 425-451.

Pineau, P. “¿Por qué triunfó la escuela?”, en La escuela como máquina de educar, Buenos Aires, Paidós, 2010, p. 134.

Rockwell, E. Los usos escolares de la lengua escrita, en Nuevas perspectivas sobre los procesos de lectura y escritura, México, Siglo XXI, 1994, pp. 296-320.

Ruíz-Ramírez, A. La enseñanza objetiva y su relación con la obra pedagógica de Pestalozzi: un proceso de recepción y reconfiguración, Colima, Universidad de Colima, 2013.

Solé, I. "Leer, lectura, comprensión: ‘hemos hablado siempre de lo mismo?", en Comprensión lectora. El uso de la lengua como procedimiento, Barcelona, Graó, 2001, pp. 15-33.

Staples, A. "El entusiasmo por la Independencia", en La educación en México, México, D. F., COLMEX, 2010, pp. 97-126.

Tanck de Estrada, D. La enseńanza de la lectura y de la escritura en la Nueva España, 1700-1821, en Historia de la lectura en México/Seminario de Historia de la Educación en México, México, D. F., COLMEX, 2010, pp. 49-93.

Vaca, J., Bustamante, A., Gutiérrez, F. y Tiburcio, C. Los lectores y sus contextos, Xalapa, Veracruz, Universidad Veracruzana, 2011.

Zea, L. El positivismo en México: nacimiento, apogeo y decadencia, México, D. F., FCE, 1968.

Zuluaga, G. y Martínez-Boom, A. "Historia de la Educación y de la Pedagogía: desplazamientos y planteamientos", en Escuela, Historia y Poder/Miradas desde América Latina. Buenos Aires, Novedades Educativas, 1997, pp. 55-75. 